\title{
Clinical, radiographic and lung function features of diffuse congenital cystic adenomatoid malformation of the lung in an adult
}

\author{
M.L. Plit, J.A. Blott, N. Lakis, J. Murray, M. Plit
}

Clinical, radiographic and lung function features of diffuse congenital cystic adenomatoid malformation of the lung in an adult. M.L. Plit, J.A. Blott, N. Lakis, J. Murray, M. Plit. @ERS Journals Ltd 1997.

ABSTRACT: Congenital cystic adenomatoid malformation of the bronchi with bilateral lung involvement has only previously been reported in one possible adult case.

This report describes a young man with bilateral diffuse lung involvement, characteristic histological features, and a mixed restrictive/obstructive lung function pattern.

Eur Respir J 1997; 10: 1680-1682.
University of the Witwatersrand, Gauteng, South Africa and National centre for Occupational Health, Johannesburg, South Africa. Correspondence: M.L. Plit, PO Box 29257, Sandringham 2131, Johannesburg, South Africa.

Keywords: Congenital cystic adenomatoid malformation, congenital cystic lung, lung function

Received: July 301996

Accepted after revision December 201996
Cystic disease of the lung, in various forms, has been well-described for over a century. Congenital cystic adenomatoid malformation (CAM) of the lung was recognized as a distinct entity of cystic lung disease by Staerk in 1897 [1], but remains a rare disorder. It is considered a developmental disorder and most of the cases reported have been described in premature or stillborn infants [1-4]. This disorder has also been described in older children and, rarely, in adults in whom the disease has been localized to one lobe or at most one lung [5-12]. The only possible adult case of CAM with bilateral lung involvement was reported by SARNELLI in 1986 [8]. It is, however, not clear from their histological description whether the features of their patient were compatible with the original description of CAM by KWITTKEN and REINER [1]. We describe the case of a 27 year old man, with bilateral, diffuse lung involvement and histological features that were compatible with a diagnosis of CAM. The clinical, radiological and lung function features are described in detail.

\section{Case Report}

The patient was a $27 \mathrm{yr}$ old man, who complained of slowly progressive dyspnoea, chronic cough productive of greenish sputum, intermittent anterior pleuritic chest pain and wheezing for 5 yrs. There were no obvious triggering factors for his respiratory symptoms. His current effort tolerance was grade 3 (Medical Research Council (MRC) criteria). He also complained of progressive weight loss but no other significant systemic symptoms, such as fever or night sweats. He had previously smoked 5-10 cigarettes daily but had stopped 2 yrs previously. There was no history of alcohol abuse. There was no history of atopy nor a familial history of respiratory disease. He had been employed as a storeman for 5 yrs. There was no history of significant dust or chemical exposure in his workplace.

On examination, his weight was $54 \mathrm{~kg}$ and height 167 $\mathrm{cm}$. His pulse was 64 beats. $\mathrm{min}^{-1}$ and blood pressure
140/80 mmHg. He was not cyanosed or clubbed, and there was no evidence of cardiac failure. His chest was hyperinflated, with prominent bilateral inspiratory and expiratory wheezing. The apex beat was not clearly palpable and the heart sounds were normal. There was no hepatosplenomegaly or significant lymphadenopathy. The rest of the findings on examination were normal.

Lung function was performed with a Jaeger Master screen (Erich Jaeger, Wuerzburg, Germany). The lung function measurements are displayed in table 1. There was no acute bronchodilator response. Furthermore, no significant improvement in lung function was noted after a 2 week therapeutic trial of prednisone, $30 \mathrm{mg} \cdot$ day $^{-1}$, with the addition of a bronchodilator. Arterial blood gas analysis in room air showed a $\mathrm{pH}$ of 7.48 , arterial carbon dioxide tension $\left(\mathrm{Pa}_{\mathrm{a}} \mathrm{CO}_{2}\right) 4.97 \mathrm{kPa} 9.92 \mathrm{kPa}$. Bicarbonate $\left(\mathrm{HCO}_{3}\right)$ was $27.6 \mathrm{mmol} \cdot \mathrm{L}^{-1}$, base excess $(\mathrm{BE})$ $3.9 \mathrm{mmol} \cdot \mathrm{L}^{-1}$, standard bicarbonate $(\mathrm{SBC}) 28.0 \mathrm{mmol} \cdot \mathrm{L}^{-1}$ and arterial oxygen saturation $\left(\mathrm{Sa}_{\mathrm{a}} \mathrm{O}_{2}\right) 95.7 \%$.

A chest radiograph showed a normal cardiac size and contour. A diffuse bilateral reticulonodular interstitial lung pattern was noted. High resolution computed tomography (HRCT) of the lung was undertaken (fig. 1). The patient was scanned from the lung apices down to the lung bases using $1 \times 10 \mathrm{~mm}$ high resolution slices. There was moderate diffuse dilatation of the trachea and main bronchi, with the anteroposterior diameter of the trachea measuring approximately $2.5 \mathrm{~cm}$. Peripheral to this, the bronchi throughout both lungs and throughout all zones of the lungs showed an unusual, dilated spiculated appearance extending all the way to the periphery of the lung fields. Cystic shadows, noted throughout the peripheral lung fields were shown to be due to peripherally dilated and beaded bronchi. Radioisotope pulmonary perfusion and ventilation scan showed subsegmental, irregular matching defects throughout both upper lobes and lingula, with less prominent involvement of the lower lobes.

Blood counts showed a total leucocyte count of $6.8 \times$ $10^{9}$ cells $\cdot \mathrm{L}^{-1}, 35 \%$ neutrophils, $56 \%$ lymphocytes, $6 \%$ 
Table 1. - Lung function measurements

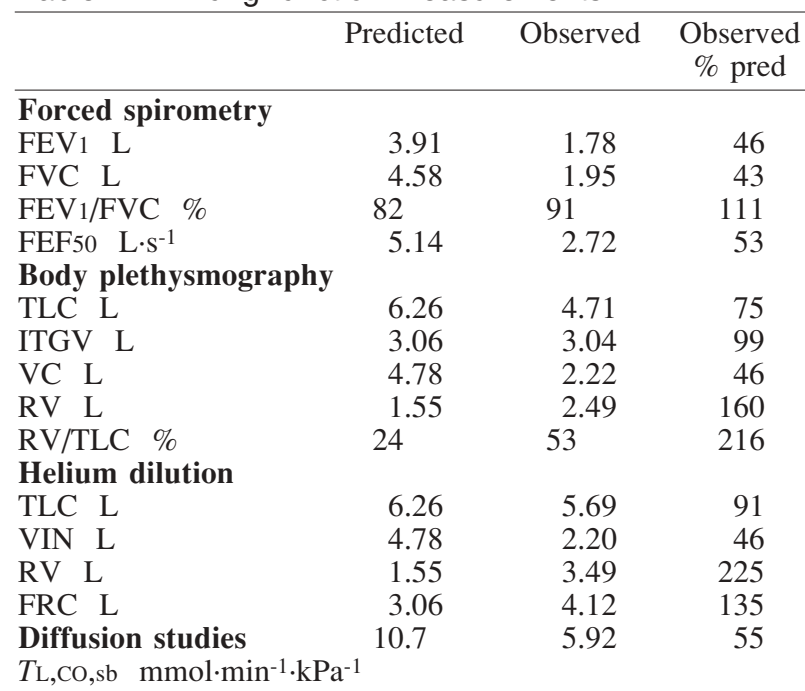

FEV1: forced expiratory volume in one second; FVC: forced vital capacity; FEF50: forced expiratory flow after 50\% of the vital capacity has been exhaled; TLC: total lung capacity; ITGV: intrathoracic gas volume; VC: vital capacity; VIN: vital capacity inspiration; RV: residual volume; FRC: functional residual capacity; $T \mathrm{~L}, \mathrm{CO}, \mathrm{sb}$ : single-breath transfer factor of the lung for carbon monoxide; $\%$ pred: percentage of predicted value.

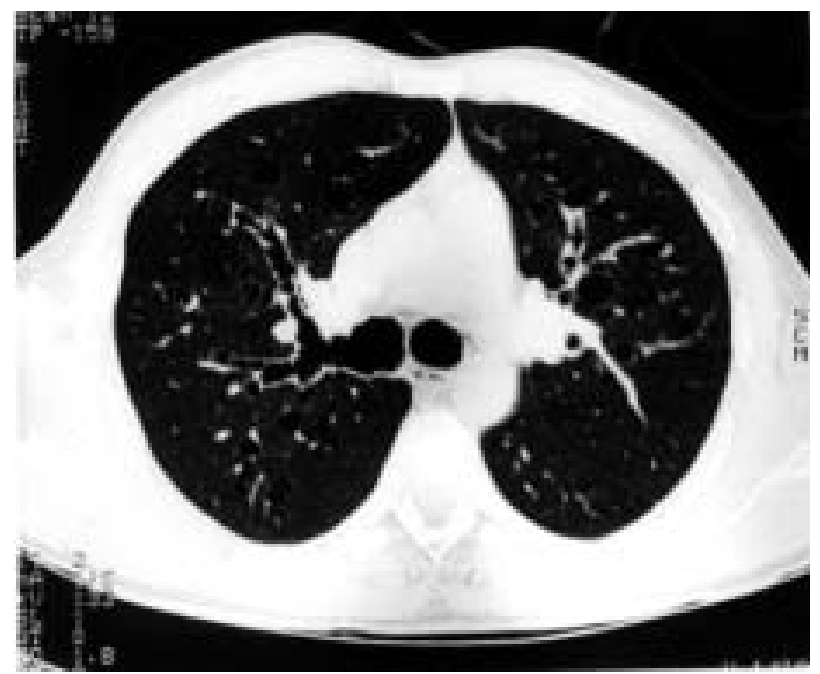

Fig. 1. - High resolution computed tomography (HRCT) scan showing shadows throughout both lung fields due to peripherally dilated bronchi.

monocytes, $3 \%$ eosinophils, and $0.5 \%$ basophils. Haemoglobin $(\mathrm{Hb})$ was $14.6 \mathrm{~g} \cdot \mathrm{dL}^{-1}$, platelet count $319 \times 10^{9} \cdot \mathrm{L}^{-1}$ platelets $\cdot \mathrm{L}^{-1}$, erythrocyte sedimentation rate (ESR) 36 $\mathrm{mm} \cdot \mathrm{h}^{-1}$, and viscosity $1.85 \mathrm{cP}$ at $25^{\circ} \mathrm{C}$. Serum urea, creatinine, electrolytes, liver enzymes and random blood glucose were normal. The Phadiotop test for mixed inhalants was negative. Serum immunoglobulin A ( $\operatorname{IgA}$ ) was 181, IgE 109, IgG 163 and $\operatorname{IgM} 108$ international units (IU). Human immunodeficiency virus I and II (HIVI and -II) enzyme-linked immunosorbent assay (ELISA) was negative. Serum alpha-1-antitrypsin was $133 \mathrm{mg} \cdot \mathrm{dL}^{-1}$. An electrocardiograph (ECG) was normal.

Fibreoptic bronchoscopy failed to confirm abnormalities. Thoracoscopic lung biopsy was undertaken, and a wedge of lung tissue measuring $4 \times 3 \times 3.5 \times 2.5 \mathrm{~cm}$ was resected. Macroscopically, the cut surface had a cystic

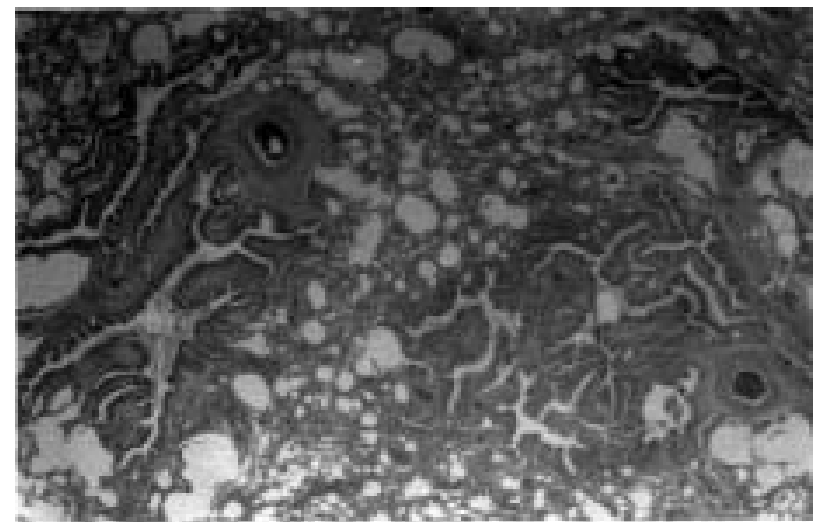

Fig. 2. - Irregular proliferation of bronchiole-like cystic spaces separated by alveoli.

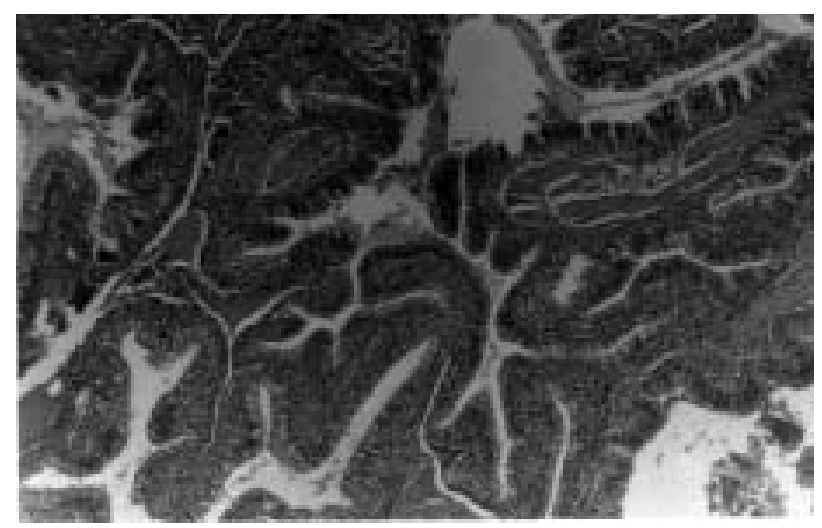

Fig. 3. - Columnar mucinous and ciliated epithelium lines the bronchiole-like cysts.

appearance, comprising thin-walled microcysts measuring up to $5 \mathrm{~mm}$ in diameter. Histological examination showed the presence of numerous small cysts, which were lined by columnar, ciliated epithelium and goblet cells (figs. 2 and 3). Smooth muscle bundles were focally prominent adjacent to some of the cysts. The cysts resembled bronchioles but were far too numerous and dilated. Some contained inspissated mucin within their lumina. These structures proliferated among alveoli, some of which were of normal size, others slightly enlarged. Cartilage was not present. The blood vessels and pleura were unremarkable. There was no significant cellular infiltrate in the interstitium. These features were considered compatible with a diagnosis of type II congenital cystic adenomatoid malformation.

\section{Discussion}

Differential diagnosis of cystic lung disease in adults included bronchiectasis, post-inflammatory pneumatoceles, bullous disease and cavitating lung infection. Congenital lesions, such as sequestration, bronchopulmonary- foregut anomalies and bronchogenic cysts are also encountered [7]. KWITTKEN and REINER [1] emphasized the characteristic histological features of CAM as being: 1) an "adenomatoid" increase of terminal respiratory structures, manifested by various-sized cysts, variably lined by cuboidal to ciliated pseudostratified columnar (bronchial type) epithelium or a single-layered cuboidal epithelium; 2) polypoid configuration of the mucosa and increased amounts of elastic tissue in the walls of the cystic portions, lined 
with bronchial-type epithelium; 3) Absence of cartilaginous plates in the cystic parenchyma, except as constituents of nondeformed bronchial structures entrapped within the diseased lung; 4) the presence of a group of mucogenic cells lining the cyst wall or alveolar-like structures; and 5) absence of inflammation.

It has been pointed out that, on rare occasions, cystic dilatation and polypoid formation may be absent, the adenomatoid structure being the only feature of the malformation [2]. Another rare variant was characterized by abundant cartilage on the walls of malformed bronchioles [11]. CAM is classified as types I-III [3]. Type I is composed of a small number of large cysts with thick smooth muscle and elastic tissue wall; relatively normal alveoli are seen between and adjacent to these cysts, and mucous glands may be present. Type II variants contain numerous smaller cysts $(<1 \mathrm{~cm}$ in diameter), with a thin muscular coat beneath the ciliated columnar epithelium; the area between the cyst is occupied by large alveolar-like structures; the lesion blends with the normal parenchyma. Type III variants occupy the entire lobe or lobes and are composed of regularly spaced bronchiole-like structures, separated by masses of cuboidal epithelium-lined alveolar-like structures.

CAM has been associated with various other congenital abnormalities, including renal agenesis, Potters' syndrome, polyhydramnios [13], and bile duct hypoplasia [14]. Adult cases have been diagnosed incidentally, presenting as mass lesions on chest radiographs [10, 15]. Cases have also been recognized after presenting with recurrent infection $[5,11]$ pneumothoraces [16], haemoptysis [17], mycetoma [16], and bronchioloalveolar carcinoma $[18,19]$.

The case reported by SARNELLi et al. [8] in 1986 was associated with severe chronic airflow limitation. In their patient, however, the lung histology showed flattened epithelial cells rather than cuboidal or ciliated pseudostratified epithelium. Their case also failed to note goblet cells, and elastic tissue appeared scant, confined mainly to subpleural regions rather than in the walls of the cystic portion.

Our patient presented with slowly progressive dyspnoea associated with diffuse multicystic lung disease, most compatible with a diagnosis of CAM. The lung function measurements showed a mixed restrictive/obstructive pattern, with reduced lung volumes associated with significantly increased residual volume and moderately decreased lung diffusion. Arterial blood gas analysis showed surprisingly good gas exchange at rest, and this was compatible with close-matching of ventilation and perfusion on radioisotope scanning. Although this lung function pattern is not pathognomonic for this disorder, as it can be seen in a variety of other conditions, it is nevertheless important to document this in view of the generalized lung involvement and the need to determine functional status and prognosis. The use of HRCT has been described either in the context of paediatric disease [20] or localized disease in adults [16]. This report emphasizes the importance of HRCT with diffuse disease, as the pathognomonic cystic bronchial wall abnormalities were not readily apparent from the plain radiograph.

Due to the paucity of adult cases reported in the literature, it has not been possible to formulate any treatment guidelines. However, the appropriate treatment of complicating lower respiratory tract infection constitutes primary therapy. Lobectomy should be considered for localized disease associated with recurrent infection and haemoptysis, but it can also be recommended that this procedure should be undertaken in asymptomatic patients in view of the relatively high incidence of malignant change, as reported previously $[18,19]$.

\section{References}

1. Kwittken J, Reiner L. Congenital cystic adenomatoid malformation of the lung. Pediatrics 1962; 30: 759-768.

2. Van Dijk C, Wagenvoort CA. The various types of congenital adenomatoid malformation of the lung. $J$ Pathol 1973; 110: 131-134.

3. Stocker JT, Madewell JE, Drake RM. Congenital cystic adenomatoid malformation of the lung; classification and morphologic spectrum. Hum Pathol 1977, 8: L155-L171.

4. Ostor AG, Fortune DW. Congenital cystic adenomatoid malformation of the lung. Am J Clin Pathol 1978; 70: 595-604.

5. Bale PM. Congenital cystic malformation of the lung: a form of congenital bronchiolar ("adenomatoid") malformation. Am J Clin Pathol 1979; 71: 411-420.

6. Miller RK, Sieber WK, Yunis EJ. Congenital adenomatoid malformation of the lung: a report of 17 cases and review of the literature. Pathol Ann 1980; 15: 387-407.

7. Hulnick DH, Naidich DP, McCauley DI, et al. Late presentation of congenital cystic adenomatoid malformation of the lung. Radiology 1984; 15: 569-573.

8. Sarnelli R, Pistolesi M, Petruzzelli S, Miniati M, Santolicandro A, Giuntini C. Fatal peripheral airway cystic disease in a young woman. Am J Med 1986; 80: 541-544.

9. Wolf SA, Hertzler JH, Phillippert AI. Cystic adenomatoid dysplasia of the lung. J Pediatr Surg 1980; 15: 825-830.

10. Avitabile AM, Hulnick DH, Greco MA, Feiner HD. Congenital cystic adenomatoid malformation of the lung in adults. Am J Surg Pathol 1984; 8: 193-202.

11. Benning TL, Godwin JD, Roggli VL, Askin FB. Cartilaginous variant of congenital adenomatoid malformation of the lung. Chest 1987; 92: 514-516.

12. Lackner RP, Thompson AB 3rd, Rikkers LF, Galbraith TA. Cystic adenomatoid malformation involving an entire lung in a 22 year old woman. Ann Thorac Surg 1996; 61: $1827-1829$.

13. Krous HF, Harper PE, Perlman M. Congenital cystic adenomatoid malformation in bilateral renal agenesis. Arch Pathol Lab Med 1980; 104: 368-370.

14. Garcia H, Heidi G, Stöhr G. Congenital cystic adenomatoid malformation of the lung associated with bile duct hypoplasia. Path Res Pract 1988; 183: 71-77.

15. Pulpeiro JR, Lopez I, Sotelo T, Ruiz JC, Garcia-Hidalgo E. Congenital cystic adenomatoid malformation of the lung in a young adult. Br J Radiol 1987; 60: 1128-1130.

16. Patz EF Jr, Müller NL, Swensen SJ, Dodd LG. Congenital cystic adenomatoid malformation in adults: CT findings. J Comput Assist Tomogr 1995; 19: 361-364.

17. Chen KTK. Congenital cystic adenomatoid malformation of the lung and pulmonary tumorlets in an adult. J Surg Oncol 1985; 30: 106-108.

18. Ribet ME, Copin M-C, Soots JG, Gosselin BH. Bronchioloalveolar carcinoma and congenital cystic adenomatoid malformation. Ann Thorac Surg 1995; 60 1126-1128.

19. Benjamin DR, Cahil JL. Bronchioloalveolar carcinoma of the lung and congenital cystic adenomatoid malformation. Am J Clin Pathol 1991; 95: 889-892.

20. Battista G, Turci GA, Pisi P, Chigi G, Zompatori M, Canini R. High-resolution computed tomography in the study of congenital cystic adenomatoid malformation of the lung. Radiol Med (Torino) 1996; 89: 416-423. 